\title{
INFLUENCE OF MOLYBDIC ACID ON MECHANICAL PERFORMANCE OF CALATROPIS FIBER REINFORCED POLYSTER COMPOSITES
}

\section{K.M.V RAVI TEJA, GOLLAPUDI KOUNDINYA, ANEGONDI SREEKAR, S T P V K A .SUDARSHAN \& MOHAMMED HAFEEZUR RAHMAN}

Assistant Professor \& Students K L University, Department of Mechanical Engineering, Guntur, Andhra Pradesh, India \begin{abstract}
The Major theme of this paper is to observe the impact of Molybdic acid on mechanical properties of (Calatropis gigantea) FRP (fiber reinforced polyster composites). The composites are made by joining $100 \%$ biodegradable Calatropis gigantea fiber as support in the reinforced polyster. Mechanical properties of composites without and with molybdic acid are prepared .In this procedure we should discover best composite for different genuine applications.

KEYWORDS: Calatropis Gigantea, Molybdic Acid, Polyster, Matrix
\end{abstract}

Received: Jun 06, 2020; Accepted: Jun 26, 2020; Published: Aug 07, 2020; Paper Id.: IJMPERDJUN2020676

\section{INTRODUCTION}

Regular strands are generally accessible everywhere throughout the globe. The pushes to utilize all the accessible regular assets including plants have prompted the creation of polymer composites. Adjacent to those plants that are created with the essential purpose behind using the fiber, some different plants fiber has discretionary or no business interest and is normally viewed as a waste. Plant, for example, banana, plantain which is delivered for its beefy organic products. The left over plantain void organic product group or stem is framed by strands of filaments and is of restricted use, being typically disposed of as trash. So this can be utilized as fiber for making fiber strengthened composites.

Composite materials have a long history of utilization. Their beginnings are obscure, yet completely written history contains references to some type of composite material. For instance, straw was utilized by the Israelites to reinforce mud blocks. Pressed wood was utilized by the old Egyptians when they understood that wood could be revamped to accomplish better quality and obstruction than warm extension just as to expanding inferable from the nearness of dampness. All the more as of late, fiber fortified pitch composites that have high solidarity toweight and firmness to-weight proportions have gotten significant in weight-touchy applications, for example, airplane and space vehicles. But only limited work has done regarding the effect of the incorporated molybdic acid as a filler into natural fiber reinforced polyster composites on the mechanical and performance of the natural fiber composites. The main goal is to investigate the effects of the addition of molybdic acid as filler on the mechanical properties of different fiber reinforced polyster composites.

\section{MATERIALS AND METHODS}

\section{Extraction Fibers}

Fibers were acquired from Local vendor (M/s kodali Arjuna Rao \&Co., India). 


\section{Fabrication}

According to the standards given by ASTM fabrication of composites are prepared by using hand layup process. In this process initially a mould should be prepared by using rubber shoe sole of required dimensions depending on the chosen property .Take a tile (mostly ceramic) and clean it by using shellac thinner (which is used for cleaning purpose only) and place the mould (which was prepared earlier) on it by using mansion hygienic wax to eliminate air gaps between mould and tile. Coat the specimen surface with polyvinyl alcohol by using a brush and mould is allowed to cure for 24 hrs. Depending upon the considerations a mixture of polyester resin, coir powder (of prescribed amount) and accelerator +catalyst should be prepared. Addition of molybidic acid was done by using sonicator. Now the prepared mixture will be poured in to the mould and a compression pressure of $0.05 \mathrm{MPa}$ will be applied on them and allowed to cure for 24 hrs .After that post curing will done for $2 \mathrm{hrs}$ at $80^{\circ} \mathrm{C}$.

\section{Mechanical Testing}

Based on the standards given by the ASTM for tensile, bending and impact testing, specimens are prepared .Identical specimens of count 5 are prepared for conducting above mentioned tests (for better accuracy).

Table 1

\begin{tabular}{|l|c|c|l|}
\hline Testing & ASTM code & Dimensions & Equipment \\
\hline Tensile & ASTMD 638M & $160 \times 12.5 \times 3 \mathrm{~mm}$ & Tensometer \\
\hline Flexural & ASTM D 790M & $100 \times 25 \times 3 \mathrm{~mm}$ & Tensometer \\
\hline Impact & ASTM D 256M & $63.5 \times 12.7 \times 10 \mathrm{~mm}$ & Charpy /Izod \\
\hline
\end{tabular}

\section{RESULTS AND DISCUSSION}

\section{Mechanical Properties}

The mechanical properties, for example, Tensile, Flexural, and impact quality of polyester composites without and with Molybdic acid are presented.

\section{NORMAL (without Molybdic acid)}

\section{Tensile Properties}

Table 2

\begin{tabular}{|c|c|c|}
\hline No of Specimen & Pure & With fiber \\
\hline 1 & 16 & 20 \\
\hline 2 & 15 & 18 \\
\hline 3 & 14 & 19 \\
\hline 4 & 17 & 22 \\
\hline 5 & 14 & 21 \\
\hline
\end{tabular}

By taking mean value of all five identical specimens a bar chart is plotted as follows 


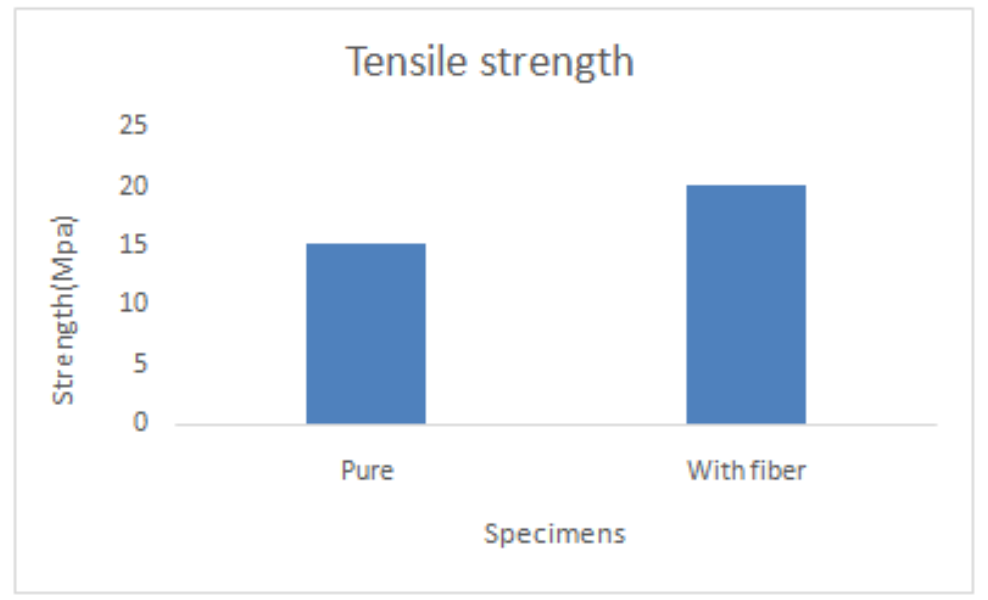

Figure 1

\section{Flexural Properties}

Table 3

\begin{tabular}{|c|c|c|}
\hline No of Specimen & Pure & With fiber \\
\hline 1 & 32 & 75 \\
\hline 2 & 35 & 77 \\
\hline 3 & 35 & 79 \\
\hline 4 & 37 & 75 \\
\hline 5 & 34 & 79 \\
\hline
\end{tabular}

By taking mean value of all five identical specimens a bar chart plotted as follows

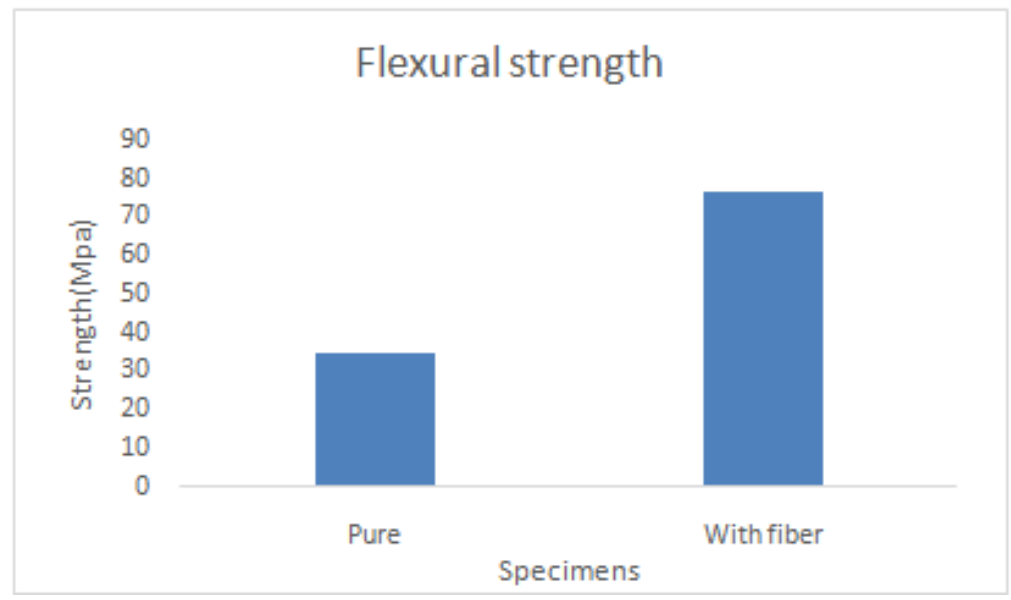

Figure 2

\section{Impact Properties}

Table 4

\begin{tabular}{|c|c|c|}
\hline No of Specimen & Pure & With fiber \\
\hline 1 & 16 & 20 \\
\hline 2 & 18 & 21 \\
\hline 3 & 16 & 23 \\
\hline 4 & 14 & 20 \\
\hline 5 & 18 & 21 \\
\hline
\end{tabular}

By taking mean value of all five identical specimens a bar chart is plotted as follows. 


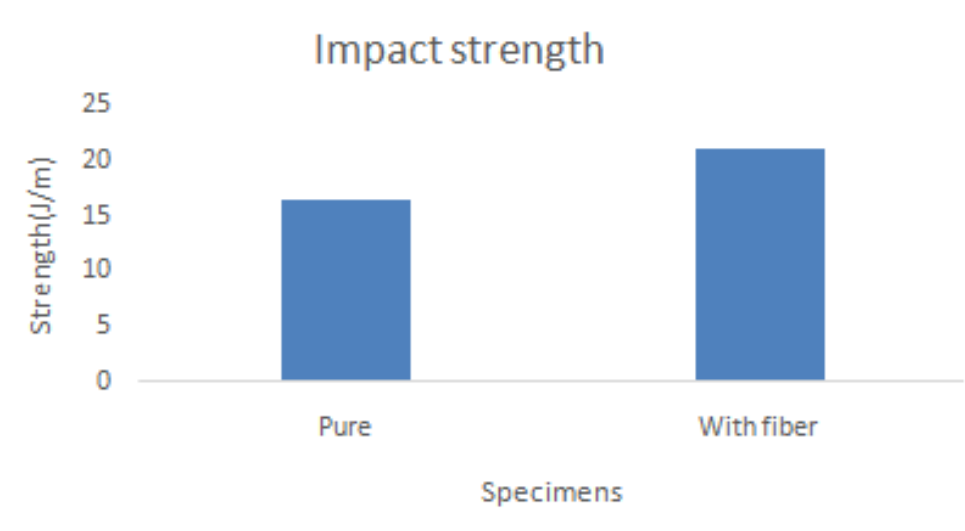

Figure 3

Table 5: Mechanical Properties of Composites

\begin{tabular}{|c|c|c|}
\hline \multicolumn{3}{|c|}{ Mechanical Properties (Without Molybdic Acid) } \\
\hline Tensile(Mpa) & Flexural(N) & Impact(J/m) \\
\hline 20 & 75 & 20 \\
\hline 14 & 77 & 21 \\
\hline 19 & 79 & 19 \\
\hline
\end{tabular}

\section{With Molybdic Acid}

Similarly five identical specimens are prepared by using molybdic acid of $2 \%$ are tested and results are given in below table.

Table 6

\begin{tabular}{|c|c|c|}
\hline \multicolumn{3}{|c|}{ Mechanical Properites (With Molybdic Acid) } \\
\hline Tensile(Mpa) & Flexural(N) & Impact(J/m) \\
\hline 32 & 102 & 28 \\
\hline 35 & 90 & 29 \\
\hline 29 & 92 & 27 \\
\hline
\end{tabular}

Comparison graphs are drawn between normal and molybdic added composites as shown below

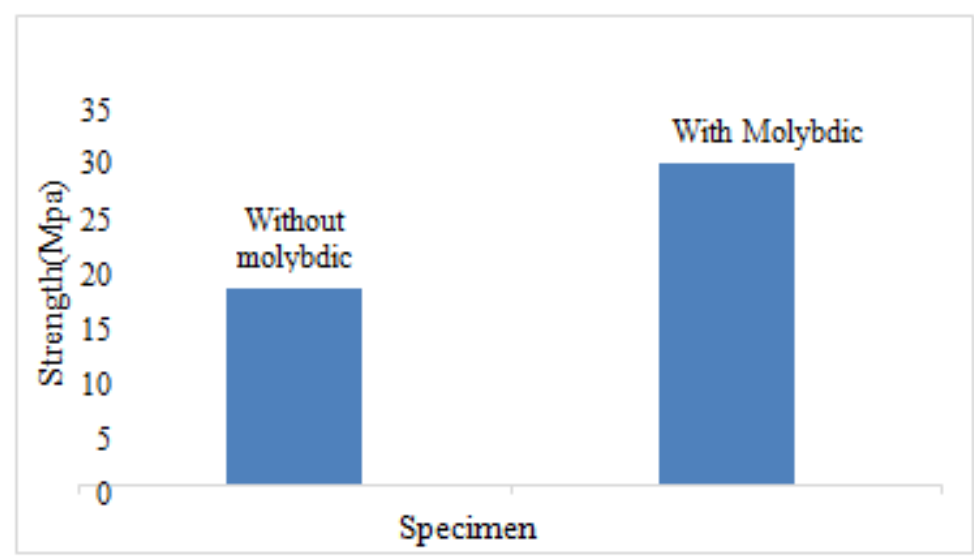

Graph 1: Tensile Strength of Composites. 


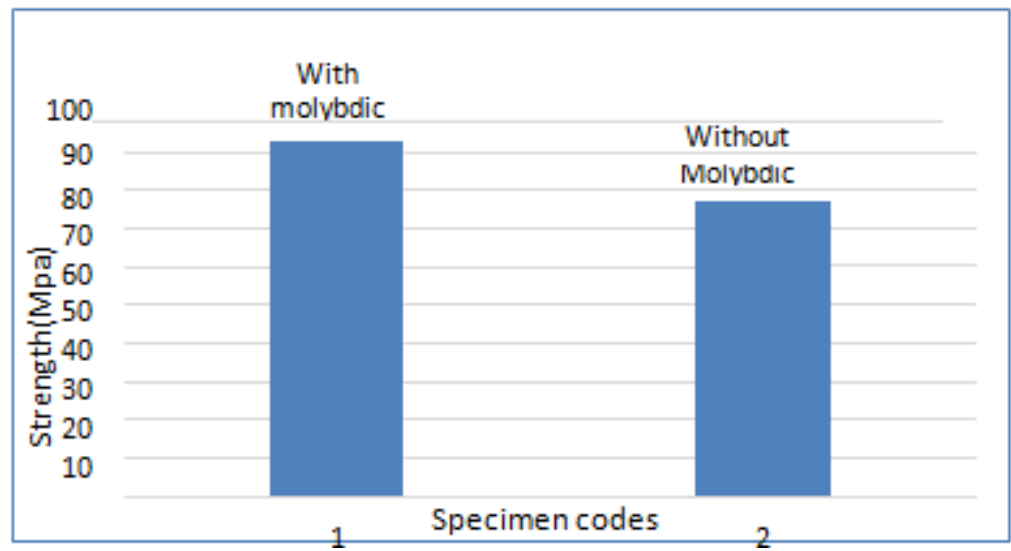

Graph 2: Flexural Strength of Composite.

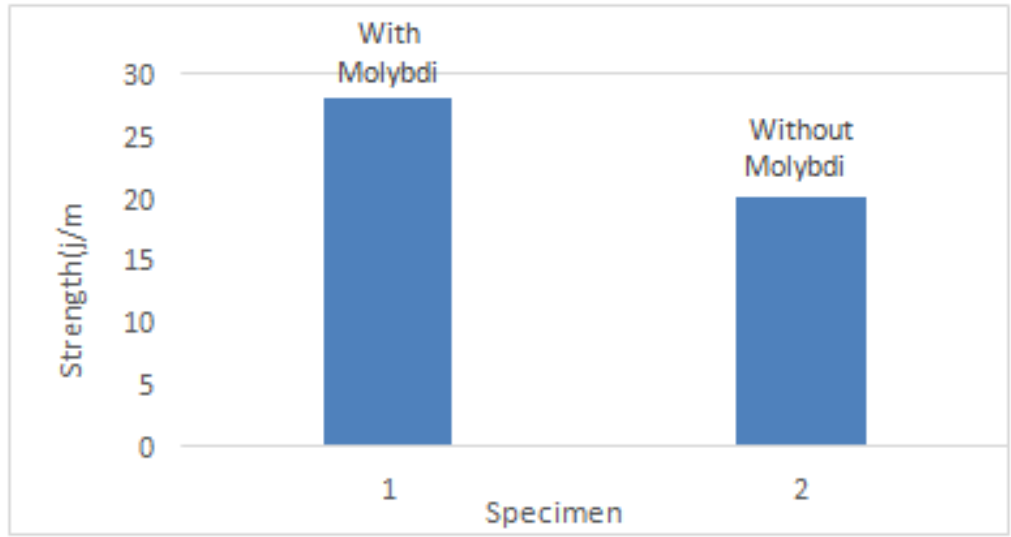

Graph 3: Impact Strength of Composites.

It is observed that composites which has molybdic acid shows better strengths in all mechanical proprieties than normal composites.

\section{CONCLUSIONS}

From the experimental results obtained, the following conclusions are drawn:

- $\quad$ By including $2 \%$ of Molybdic acid additionally we can enhance the strength and modulus.

- It has been observed that there is an appreciable increment in properties (tensile, flexural, impact ) on addition of Molybdic acid

\section{REFERENCES}

1. C.P. Chimekwene, E.A. Fagbemi and P.O Ayeke." Mechaical Properties of Plantain Empty Fruit Bunch Fiber Reinforced Epoxy Composite" Volume2, Issue 6(June 2012) ISSN: 2250-0588.

2. V Ratna Prasad, K Mohana Rao \& G Nagasrinivasulu," Mechanical properties of banana empty fruit bunch fibre reinforced polyester composites", Indian Journal of Fibre \& Textile Research Vol. 34, June 2009, pp. 162-167

3. Ivone L. Santana; Edméa Lodovici; Jivaldo R. Matos; Igor S. Medeiros; Caroline L. Miyazaki; Leonardo E. RodriguesFilho",Effect of experimental heat treatment on mechanical properties of resin composites",Braz. Dent. J. vol.20 no.3 Ribeirão Preto 2009 
4. H. Ku, H. Wang, N. Pattarachaiyakoop, M. Trada, A review on the tensile properties of natural fiber reinforced polymer composites, Composites: Part B 42 (2011) 856-873

5. V. Manikandan, J.T. Winowlin Jappes, S.M. Suresh Kumar, P.Amuthakkannan "Investigation of the effect of surface modifications on the mechanical properties of basalt fibre reinforced polymer composites", Composites: Part B 43 (2012) $812-818$

6. Tong Yuanjian 1, D.H. Isaac, "'Impact and fatigue behaviour of hemp fibre composites", Composites Science and Technology 67 (2007) 3300-3307

7. Sreenivasan VS, Soma Sundram S, Ravindran D, Manikandan V, Naryanaswamy R, Materials and Design, 32 (2011) 453.

8. H. Anuar , A. Zuraida, "Improvement in mechanical properties of reinforced thermoplastic elastomer composite with kenaf bast fibre”, Composites: Part B 42 (2011) 462-465

9. Flavio de Andrade Silva a, Nikhilesh Chawla b, Romildo Dias de Toledo Filho a, "Tensile behavior of high performance natural (sisal) fibers", Composites Science and Technology 68 (2008) 3438-3443

10. Nitinat Suppakarn, Kasama Jarukumjorn, "Mechanical properties and flammability of sisal/PP composites Effect of flame retardant type and content", Composites: Part B 40 (2009) 613-618

\section{AUTHORS PROFILE}

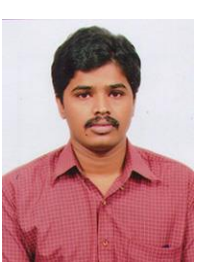

K.M.V Ravi Teja is an Assistant Professor - Department of Mechanical Engineering at Koneru Lakshmaiah Education Foundation, INDIA. He holds a Master's degree in the field of Thermal Engineering. He research is oriented towards composites \& Alternative Fuels.

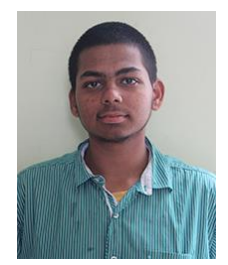

Gollapudi Koundinya is a Final year Student in the Department of Mechanical Engineering at Koneru Lakshmaiah Education Foundation, INDIA. His research is oriented towards the Composite materials.

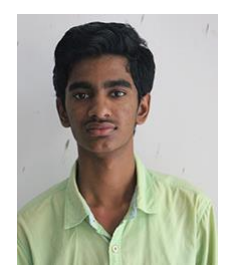

Anegondi Sreekar is a Final year Student in the Department of Mechanical Engineering at Koneru Lakshmaiah Education Foundation, INDIA. His research is oriented towards the Composite materials. 


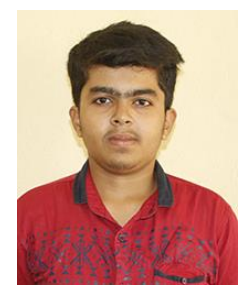

Mohammed Hafeezur Rahman is a Final year Student in the Department of Mechanical Engineering at Koneru Lakshmaiah Education Foundation, INDIA. His research is oriented towards the Composite materials.

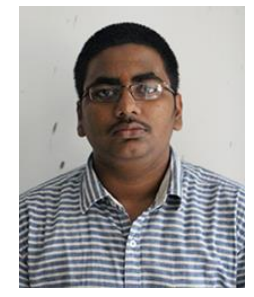

S T P V K A .Sudarshan is a Final year Student in the Department of Mechanical Engineering at Koneru Lakshmaiah Education Foundation, INDIA. His research is oriented towards the Composite materials. 

